\title{
A BUSCA DA INTERDISCIPLINARIDADE NAS DISCIPLINAS DE PROJETO ARQUITETÔNICO NO CURSO DE GRADUAÇÃO EM ARQUITETURA E URBANISMO
}

\author{
Djanine Dolovet Martins, Adriana Aparecida de Lima Terçariol \\ Universidade do Oeste Paulista - UNOESTE, Curso de Arquitetura e Urbanismo, Presidente Prudente, SP. E-mail: \\ djanine@unoeste.br
}

\begin{abstract}
RESUMO
O intuito deste trabalho é o de apresentar como a disciplina de Projeto Arquitetônico, especificamente, do curso de Arquitetura e Urbanismo ofertado pela referida Universidade, necessita e depende de uma organização interdisciplinar, envolvendo todas as disciplinas da grade curricular do curso. Para o desenvolvimento deste estudo, optou-se pela pesquisa bibliográfica e documental como metodologia de investigação. Na pesquisa bibliográfica as principais obras consultadas foram: Fazenda (1999, 1979), Morin (2007), Japiassu (1976), Luck (2001), Freire (2009). Na análise documental, adotou-se como referência o Projeto Pedagógico do Curso de Arquitetura e Urbanismo desenvolvido na Unoeste e diretrizes que fundamentam a estruturação de projetos de curso de graduação na área de Arquitetura e Urbanismo. Como principais resultados, concluiu-se que a disciplina de Projeto Arquitetônico necessita dessa interdisciplinaridade, envolvendo todas as demais disciplinas do curso, pois um Projeto Arquitetônico depende também de todo um aprendizado sobre diversas áreas para sua concretização.
\end{abstract}

Palavras-chave: Interdisciplinaridade; Arquitetura e Urbanismo; Projeto Arquitetônico; Ensino Superior.

\section{INTERDISCIPLINARITY SEARCH OF THE ARCHITECTURAL DESIGN COURSES IN THE GRADUATE COURSE IN ARCHITECTURE AND URBAN PLANNING}

\begin{abstract}
The purpose of this paper is to present how the discipline of Architectural Design, specifically, the course of Architecture and Urbanism offered by that university, needs and depends on an interdisciplinary organization, involving all disciplines of the curriculum of the course grade. To develop this study, we opted for the bibliographical and documentary research as research methodology. In literature the main works were consulted: Finance (1999 1979), Morin (2007), Japiassu (1976) Luck (2001), Freire (2009). In document analysis, it was adopted as reference the Educational Project Architecture and Urbanism Course developed in Unoeste and guidelines that support the structure of undergraduate course projects in Architecture and Urbanism area. As main results, it was concluded that the discipline of Architectural Design needs this interdisciplinary approach, involving all the other disciplines of the course, as one architectural design also depends on a whole learning about different areas for its implementation.
\end{abstract}

Keywords: Interdisciplinarity, Architecture and Urbanism, Architectural Design, Higher Education 


\section{INTRODUÇÃO}

Os processos de ensino-aprendizagem nas disciplinas do curso de Arquitetura e Urbanismo diferem significativamente do ensino tradicional brasileiro. Atualmente, muitas das diversas disciplinas ministradas nesses cursos são divididas em uma parte teórica e a outra prática, sendo esta última realizada geralmente em ateliê ou laboratórios. Esta prática atual vem sendo seguida em parte desde a Bauhaus, escola alemã de ensino das artes, design e arquitetura, fundada em 1919, nela os processos de ensino dessas áreas do conhecimento começaram a ser alterados, tendo chegado ao Brasil tardiamente, mas com grandes transformações práticas. $\mathrm{O}$ ensino estava baseado na reflexão prática e estilística nos ateliês e oficinas, com acompanhamento e direcionamento dos docentes (LOURENÇO; RIBEIRO, 2007).

Segundo Fontoura (2009), a base pedagógica da Bauhaus rejeitava o modelo de ensino focado na transmissão de informações, priorizando a auto formação do aluno, por meio da integração entre ensino teórico e prático nas oficinas, laboratórios e ateliês. Fato que ocorre atualmente nas escolas de graduação de Arquitetura e Urbanismo.

Reyes (2001) afirma que tradicionalmente arquitetos adquirem, dentro da sua formação, conhecimentos sobre como projetar seus respectivos objetos de estudo. Aprende-se a projetar na prática é uma frase que reflete o infrutífero esforço dos muitos que lidam com ensino da disciplina de Projeto Arquitetônico.

O objetivo deste trabalho é o de apresentar como a disciplina de Projeto Arquitetônico, especificamente, do curso de Arquitetura e Urbanismo de uma Universidade Privada de Presidente Prudente/SP, precisa ser desenvolvida de forma interdisciplinar, ou seja, apresentando uma inter-relação com as demais disciplinas da grade curricular do curso, pois para sua formação como arquiteto o aluno precisara inter-relacionar todo o conteúdo de aprendizado para uma futura prática profissional, um Projeto Arquitetônico não se realiza somente pelo próprio projeto, dependendo este de todo um aprendizado sobre diversas áreas para sua concretização.

\section{METODOLOGIA}

Para o desenvolvimento deste estudo, optou-se pela pesquisa bibliográfica e documental como metodologia de investigação. $\mathrm{Na}$ pesquisa bibliográfica as principais obras consultadas foram: Fazenda (1999, 1979), Morin (2007), Japiassu (1976), Luck (2001), Freire (2009). Na análise documental, adotou-se como referência o Projeto Pedagógico do Curso de Arquitetura e Urbanismo da Universidade do Oeste 
Paulista (Unoeste/Presidente Prudente/SP) e diretrizes que fundamentam a estruturação de projetos de curso de graduação na área de Arquitetura e Urbanismo.

\section{RESULTADOS}

Segundo Nogueira

interdisciplinaridade é o trabalho de integração das diferentes áreas do conhecimento, um real trabalho de cooperação e troca, aberto ao diálogo e ao planejamento. A interdisciplinaridade tem como proposta promover uma nova forma de trabalhar o conhecimento, na qual haja interação entre sujeitos-sociedadeconhecimentos na relação professor-aluno, professor-professor e aluno-aluno, de maneira que o ambiente escolar seja dinâmico e vivo e os conteúdos e/ou temas geradores sejam problematizados e vislumbrados juntamente com as outras disciplinas.

Morin (2007) enfatiza a problemática da fragmentação das disciplinas e dos currículos, dificultando a interdisciplinaridade na educação. Evidencia o desenvolvimento de uma educação que desempenha a interrelação do indivíduo/espécie/sociedade de forma indissociável, pois, ao mesmo tempo, recobra a identidade do sujeito, fazendo-o numa profunda relação com os outros e o planeta.

As relações interdisciplinares na Arquitetura e no Urbanismo existem como princípio, pois essas áreas do conhecimento partem das relações - ambiente (construído) habitante e seu comportamento. A problematização, as análises, os diagnósticos, a definição de soluções e a implementação de diferentes intervenções, abrangendo o homem e seu habitat, seriam mais adequadamente abordadas se houvesse uma atuação de equipe interdisciplinar, sendo que os níveis de abordagem dependeriam da escala do problema, dos objetivos a serem alcançados e do nível pretendido para a solução e seu impacto ambiental.

Hernández (1998) chama Projeto de trabalho o enfoque integrador da construção de conhecimento que transgride o formato da educação tradicional de transmissão de saberes compartimentados e selecionados pelo/a professor/a e reforça que o projeto não é uma metodologia, mas uma forma de refletir sobre a escola e sua função. Como tal, sempre será diferente em cada contexto.

Hernández aponta como possíveis etapas do projeto: determinar com o grupo a temática a ser estudada e princípios norteadores; definir etapas; planejar e organizar as ações - divisão dos grupos, definição dos assuntos a serem pesquisados, procedimentos e delimitação do tempo de duração; socializar periodicamente os resultados obtidos nas investigações (identificação de conhecimentos construídos); estabelecer com o grupo os critérios de avaliação; avaliar cada etapa do 
trabalho, realizando os ajustes necessários; fazer o fechamento do projeto propondo uma produção final, como elaboração de um projeto executivo no caso dos estudantes da graduação de arquitetura e urbanismo.

Esta forma de organização de saberes que vai se construindo como uma rede, sensibiliza alunos e alunas para aquilo que Ihes interessa ou preocupa, legitimando a função social da escola. Possibilita a validade do conhecimento aprendido, resultando numa melhor decisão para a qualidade de vida na sociedade e reconhece o sujeito cidadão, capaz de se inserir no pensamento coletivo para o compartilhamento de espaços e serviços comuns.

\section{O Método de Projetos}

Aprende-se através da reconstrução consciente da experiência" (DEWEY, 1973. p. 33), experiência esta adquirida em sua vida no cotidiano e nas outras disciplinas que integram a grade curricular do curso de arquitetura e urbanismo para assim se sintetizar na concepção do projeto arquitetônico.

Segundo Hernandez (1998), dois fatores influenciaram nas mudanças da educação escolar e explicam porque os projetos voltam a ser objeto de interesse. De uma lado, da revolução cognitiva, ou seja, da forma de entender o ensino, a aprendizagem e as mudanças nas concepções sobre o conhecimento e o saber oriundo das novas tecnologias de armazenamento, tratamento e distribuição da informação.

O Projeto é, portanto, a resignificação do espaço escolar, tornando a sala de aula um ambiente dinâmico de interação, de relações pedagógicas e de construção do conhecimento. É mais do que uma forma de organizar o conhecimento escolar, pois, implica numa mudança de currículo e, conseqüentemente, numa mudança da própria escola; no caso do curso de Arquitetura e Urbanismo implica na criação das salas de aula, chamada de ateliês, onde ao invés de carteiras convencionais temos mesas maiores para realização dos projetos e atividades multidisciplinaridades envolvendo a arte de criação, lúdicas e desenvolvimento técnico, implica no desenvolvimento de um trabalho pedagógico cooperativo, compartilhado e de estudo de conteúdos para além do escolar, ou seja, numa visão de globalização relacional.

Dessa forma, a função do projeto é possibilitar a criação de estratégias para facilitar a aprendizagem e a construção do conhecimento. Trata-se de ensinar o aluno a aprender, a encontrar o nexo, a estrutura, o problema vinculado à informação que se quer e que permite a aprendizagem de forma interdisciplinar.

O projeto arquitetônico, elaborado durante o transcorrer da disciplina, é gradualmente construído segundo um determinado processo em que previamente 
se definem as etapas que o compõem. 0 aprendiz, elaborador do projeto, torna-se, portanto um sujeito ativo no processo de aprendizado, construindo e reconstruindo o conhecimento, sobre orientação e mediação de um professor que conduza o processo por conta de sua competência.

\section{Etapas do Processo de Projeto Arquitetônico}

As etapas de processo do Projeto Arquitetônico aqui apresentado, independem de metodologias projetuais, as quais podem se diferenciar de docente para docente. A análise dos estudos sobre o processo de projeto, seus princípios e métodos, bem como as filosofias e teorias mostram que as pesquisas sobre 0 projeto são interdisciplinares (KOWALTOWSKI; MOREIRA; PETRECHE; FABRÍCIO, 2011, p. 151).

O projeto não deve ser confundido com arte, ciência, engenharia ou matemática, que possuem um campo de conhecimento específico. Por exemplo, em arquitetura o projeto de um edifício envolve o conhecimento da área de engenharia estrutural, mecânica, elétrica, hidráulica e dos confortos térmicos, acústico, funcional e luminoso.
E ainda há o envolvimento da estética em fatores como volumes, forma, material e cor. [...] O estudo nas áreas científicas é realizado com princípios que substituem sistematicamente a literatura científica da qual derivam o que leva o cientista a ser direcionado na escolha de problemas e na forma da solução. Na área de projeto, o estudo se faz com leituras dos clássicos da área, de assuntos relevantes de outras áreas (psicologia, arte, ciências sociais), de relatórios recentes de pesquisa e de alguns manuais. Disso resulta o conhecimento de uma variedade de problemas e soluções que podem ser conflitantes e incomensuráveis. (KOWALTOWSKI; MOREIRA; PETRECHE; FABRÍCIO, 2011, p. 152).

O mapa conceitual do processo de Projeto Arquitetônico, apresentado abaixo, demonstra as diversas relações que temos com as demais disciplinas para elaboração de um único Projeto Arquitetônico, evidenciando que todas se inter-relacionam em um único processo final que chamamos de Projeto Arquitetônico. 


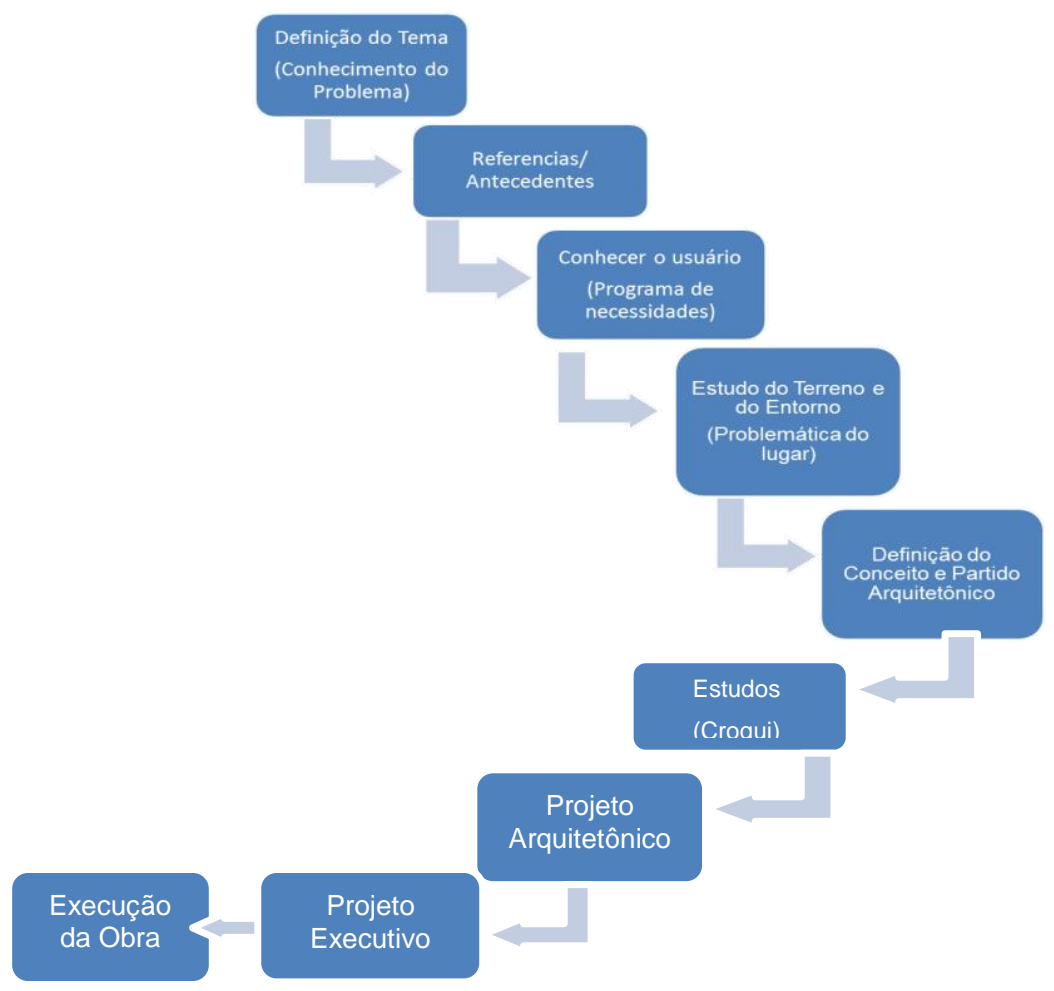

Figura 1. Mapa Conceitual - Processo do Projeto Arquitetônico.

\section{DISCUSSÃO}

Aprende-se através da reconstrução consciente da experiência" (DEWEY, 1973. p. 33), experiência esta adquirida em sua vida no cotidiano e nas outras disciplinas que integram a grade curricular do curso de arquitetura e urbanismo para assim se sintetizar na concepção do projeto arquitetônico.

Segundo Hernandez (1998), dois fatores influenciaram nas mudanças da educação escolar e explicam porque os projetos voltam a ser objeto de interesse. De uma lado, da revolução cognitiva, ou seja, da forma de entender o ensino, a aprendizagem e as mudanças nas concepções sobre o conhecimento e o saber oriundo das novas tecnologias de armazenamento, tratamento e distribuição da informação.

O Projeto é, portanto, a resignificação do espaço escolar, tornando a sala de aula um ambiente dinâmico de interação, de relações pedagógicas e de construção do conhecimento. É mais do que uma forma de organizar o conhecimento escolar, pois, implica numa mudança de currículo e, conseqüentemente, numa mudança da própria escola; no caso do curso de Arquitetura e Urbanismo implica na criação das salas de aula, chamada de ateliês, onde ao invés de carteiras convencionais temos mesas maiores para realização dos projetos e atividades multidisciplinaridades envolvendo a arte de criação, lúdicas e desenvolvimento técnico, implica no 
desenvolvimento de um trabalho pedagógico cooperativo, compartilhado e de estudo de conteúdos para além do escolar, ou seja, numa visão de globalização relacional.

Nessa perspectiva, Hernandez (1998) aponta aspectos em que o trabalho com Projetos pode contribuir para que o aluno desenvolva capacidades relacionadas com: a autodireção que favorece a realização de tarefas de pesquisa.

As escolas de Arquitetura em sua maioria formam os profissionais com base em currículos cuja organização dificulta a integração entre as diversas disciplinas. O estudante tem dificuldades para ver a relação prática entre elas no desenvolvimento de um projeto ou execução de um determinado empreendimento. Isto sem mencionar os aspectos didáticos que acabam por agravar a aprendizagem, devido a metodologias de ensino que consideram muito mais a questão do como ensinar do que o como aprender.

Para Almeida (2007), um dos desafios no ensino-aprendizado de Projeto é a interação entre a subjetividade, a intersubjetividade e a objetividade, visto que, quanto à introdução ao projeto de Arquitetura, os professores adotam determinados expedientes pedagógicos cujo centro é a criatividade a partir do sujeito projetista. Essa pedagogia leva, invariavelmente, a certas ênfases, como: valorização das qualidades individuais; utilização da arte para a composição volumétrica, ordenamento espacial, representação e comunicação; trabalho individual sem articulação com o coletivo, o que reforça a competição entre os estudantes e; a descontextualização do projeto. Dentre os aspectos importantes que são abandonados na pedagogia introdutória à disciplina, estão o olhar crítico de Arquitetura, o saber técnico e o trabalho cooperativo entre os estudantes, além do uso e da responsabilidade ambiental e social da Arquitetura quanto às relações entre comunidade e natureza, corpo e espaço social.

Conforme descrito por Atanasio, Pereira e Pereira (2007), ao longo da prática em Arquitetura, verifica-se que estudantes e profissionais muitas vezes possuem habilidades mais artísticas que técnicas e vice-versa, sendo que os artistas, em geral, são mais criativos, falam mais de imagens que razão e possuem uma visão holística das coisas, enquanto que os racionalistas ou tecnicistas são melhores em predizer o desempenho dos edifícios, em matemática, e solucionam melhor os problemas. A prática do ateliê tende a favorecer os alunos que possuem habilidades mais artísticas, fazendo com que o estudante seja recompensado pela não-importância dada aos assuntos técnicos. 
CONCLUSÃO

A efetivação de um trabalho interdisciplinar, tanto em pesquisa, quanto em sala de aula, vai além da integração de diferentes áreas, pois a interdisciplinaridade pressupõe a construção incessante das relações entre docentes, que ultrapassa a simples unificação de saberes. Para isso, fazse necessário o real profissionalismo do professor, ou seja, a competência em sua área de atuação, ao método de seu saber (disciplina ou especialidade).

A ótica da interdisciplinaridade se fundamenta na construção e reconstrução de saberes, possibilitando um vasto espaço para o conhecimento e aprimoramento dos próprios sujeitos. Nesse sentido, a interdisciplinaridade não trabalha 0 conhecimento de maneira globalizante, a fim de unificar os saberes, mas busca promover interconexões entre os saberes, tanto entre professores e seus pares, quanto entre professores e alunos, trabalhando $\mathrm{o}$ conhecimento de forma problematizadora e estabelecendo relações entre as diferentes ciências, o cotidiano acadêmico e a realidade social/histórica em que os sujeitos estão envolvidos.

Na Arquitetura e no Urbanismo, em algumas situações - e provavelmente de modo equivocado - destaca-se de um lado, o método científico e, de outro lado, a via rápida, visando encurtar etapas do processo para se chegar ao produto, utilizando-se para isso, apenas algumas técnicas e ferramentas. Talvez essa situação - muito comum em países em desenvolvimento como o nosso ocorra devido a exigências do cliente e a pouca compreensão que a sociedade tem do papel do projetista, do profissional de arquitetura e do urbanismo e, por conseguinte, de um projeto incompleto e seu desempenho negativo no ambiente construído no decorrer do uso em termos de seu impacto na saúde física e mental de seus usuários (EVANS \& MC COY, 1998).

\section{REFERÊNCIAS}

ATANASIO, V.; PEREIRA, F. O. R.; PEREIRA, A. T. C. Utilização de um modelo analítico para a implementação de um método inovador para o ensino de iluminação natural em Arquitetura. Ambiente Construído, Porto Alegre, v. 7, n. 3, p. 129-142, jul./set. 2007.

COSTA, L.; XAVIER, A. Lucio Costa: sobre uma Arquitetura. Porto Alegre: Universitário Rotter dos Reis, 2007.

DEWEY, J.. Escola e democracia. São Paulo: Vozes, 1973. Vida e educação. São Paulo. Edições Melhoramentos.19-

EVANS, G. W.; McCoy, J. M. When buildings don't work: the role of architecture in human health. Journal of Environmental Psychology, v.18, n. 1, p.85-94. 1998.

FAZENDA, I. C. A. Didática e interdisciplinaridade. Campinas, SP: Papirus, 1999.

FAZENDA, I. C. Integração e interdisciplinaridade no ensino brasileiro: efetividade ou ideologia. São Paulo: Loyola, 1979. 
FONTOURA, A. M. Bauhaus. A pedagogia da ação. Revista ABCDesign, 2009. Disponível em:

<http://abcdesign.com.br/teoria/bauhaus-apedagogia-da-acao/>. Acesso em: 14 jul. 2012.

FORD, M. J.; FORMAN, E. A. Chapter 1: Redefining Disciplinary Learning in Classroom Contexts. Review of Research in Education, Thousand Oaks, v. 30, n. 1, p. 132, 2006.

http://dx.doi.org/10.3102/0091732X0300010 $\underline{01}$

FREIRE, P. Pedagogia da autonomia : saberes necessários à prática educativa. São Paulo: Paz e Terra, 2009.

FORTES, C. C. Interdisciplinaridade: Origem, Conceito e Valor . In: Módulo 6 - Avaliação do Ensino e da Aprendizagem. Curso de Especialização. Presidente Prudente: UNOESTE, 2013.

HERNÁNDEZ, F. Transgressão e mudança na educação: os projetos de trabalho. Porto Alegre: Artmed, 1998.

JAPIASSU, H. Interdisciplinaridade e patologia do saber. Rio de Janeiro: Imago, 1976.

KOWALTOWSKI, D. C. K. C. et al. O processo de projeto em Arquitetura. São Paulo: Oficina de Textos, 2011.

LEITE, L. H. A.; MENDEZ, V.. Os Projetos de Trabalho: Um espaço para viver a diversidade e a democracia na escola. Revista de Educação, Porto Alegre: Projeto, v 3, n.4, p.25-29, jan./jun. 2000.

LOURENÇO, C. A.; RIBEIRO, S.M. História e Pedagogia: a influência da Bauhaus para o ensino do Design. Actas de Diseños 3, ano 2, n. 3, p. 175-177, jun. 2007. Disponível em: <http://fido.palermo.edu/servicios_dyc/publi cacionesdc/archivos/11_libro.pdf>. Acesso em: 14 jul. 2012.
LUCK, H. Pedagogia da interdisciplinaridade. Fundamentos teórico-metodológicos.

Petrópolis: Vozes, 2001.

MORIN, E. Os sete saberes necessários a educação do futuro. São Paulo: Cortez, 2007.

MORAN, J. M. Mudar a forma de ensinar e de aprender com tecnologias - transformar as aulas em pesquisa e comunicação presencial-virtual. Disponível em: <http://www.eca.usp.br/prof/moran/uber.ht m>. Acesso em: 15 jul. 2012.

NOGUEIRA, N. R. Interdisciplinaridade Aplicada. São Paulo: Érica, 1998.

REYES, J. A. A. Expressão Gráfica e Novos Meios Educativos: metodologias coletivas para o ensino de projeto em engenharia e arquitetura . Revista Escola de Minas, v. 54, n.1, 2001. Disponível em: <http://dx.doi.org/10.1590/S037044672001000100010>. Acesso em: 15 fev. 2013.

VELOSO, M. F. D.; ELALI, G. A. Há lugar para o projeto de arquitetura nos estudos de pósgraduação? [S.I.], jan. 2002. Disponível em: $<$ http://

www.vitruvius.com.br/arquitextos/arq000/es p117.asp>. Acesso em: 21 nov. 2014.

VELOSO, M. F. D.; MARQUES, S. A pesquisa como elo entre prática e teoria do projeto: alguns caminhos possíveis. [S.I.], set. 2007. Disponível em: $<$ http://www.vitruvius.com.br/arquitextos/ar q000/esp438.asp>. Acesso em: 21 nov. 20014.

ZABALA, A. A Prática educativa: como ensinar. Porto Alegre: ArtMed, 1998.

Recebido para publicação em 19/08/2015

Revisado em 02/09/2015

Aceito em 10/09/2015 